\title{
Nest Site Characteristics and Factors Affecting Nest Success of Greater Sage-grouse
}

\author{
James L. Rebholz ${ }^{1}$, W. Douglas Robinson ${ }^{1, *}$ and Michael D. Pope ${ }^{2}$ \\ ${ }^{1}$ Department of Fisheries and Wildlife, Oregon State University, Corvallis, OR 97331, USA and ${ }^{2}$ Oregon Department of \\ Fish and Wildlife, 3406 Cherry Avenue NE, Salem, OR 97303, USA
}

\begin{abstract}
Nesting success of greater sage-grouse (Centrocercus urophasianus) influences annual reproductive success and population dynamics. To describe nesting habitat and measure the effects of vegetation characteristics on nesting outcomes, we sampled 87 sage-grouse nests during 2004 and 2005 in the Montana Mountains of northwestern Nevada. Within a $78.5-\mathrm{m}^{2}$ circular plot surrounding each nest, we quantified sagebrush canopy cover and grass cover. We used Akaike's Information Criterion to rank competing models describing potential relationships between vegetation characteristics at and surrounding sage-grouse nests and to determine those characteristics associated with nest success. Nest initiation rate was high (90.0\%) and apparent nest success was $40.2 \%$. We used a Mayfield estimation to determine a probability of nest success (hatch $\geq 1$ chick) of $36 \%$. Grass cover within a $3-\mathrm{m}^{2}$ area centered on the nest had a positive effect on nest success (odds ratio: 1.03, 95\% CI: $1.005-1.059$ ). We also found weak support for a positive effect on nest success of sagebrush cover at the nest (odds ratio: 1.02, 95\% CI: $0.993-1.043$ ). Our results are similar to previous findings and confirm the importance of sagebrush cover and herbaceous understory for nesting. To manage sagebrush communities for successful nesting by greater sage-grouse, we recommend providing sufficient grass and sagebrush cover.
\end{abstract}

Key Words: Centrocercus urophasianus, Greater sage-grouse, Nesting habitat, Nest success, Nevada, Radiotelemetry.

\section{INTRODUCTION}

The distribution and population densities of greater sagegrouse (Centrocercus urophasianus) have declined since European settlement of western North America in the late $19^{\text {th }}$ and early $20^{\text {th }}$ centuries [1]. Sage-grouse were widespread, with documented occurrences in $13 \mathrm{U}$. S. states and 3 Canadian provinces [2]. There were $\geq 1,200,000 \mathrm{~km}^{2}$ of potential habitat for sage-grouse prior to European settlement but overgrazing, conversion to agriculture, altered fire regimes, sagebrush eradication and introduction of exotic vegetation have led to the loss of $\geq 40 \%$ of suitable habitat in the last century [2-5].

Sagebrush communities in Nevada have been affected by the same factors degrading sage-grouse habitat across their geographic range. Sage-grouse population declines were reported as early as the 1930s [6,7]. Currently, the mean decline in Nevada is estimated at $50 \%$ with some local populations declining by $80 \%$ (Nevada Wildlife Federation, unpublished report). Declines are thought to have been caused by reduced reproductive success [4].

Despite a similar history of habitat loss that impacted populations throughout the state, the Montana Mountains in northwestern Nevada support one of the highest densities of sage-grouse in the state and reproductive success appears to be high. Based on harvest data collected from marked birds between 2001 and 2005, population estimates in the Montana Mountains were between 7,264 and 13,625 and annual

*Address correspondence to this author at the Department of Fisheries and Wildlife, Oregon State University, Corvallis, OR 97331, USA; Tel: 5417379501; Fax: 5417373590; E-mail: douglas.robinson@oregonstate.edu production has been as high as 3.02 chicks per hen (E. Partee, Nevada Division of Wildlife, unpublished report).

Clutch size, nesting and renesting rates, nest success, and ratios of chicks per hen have been used to assess the reproductive success of sage-grouse populations [1]. Regardless of the index of reproductive success, variation may result from differences in habitat availability and quality. The loss of nesting habitat is hypothesized to be a primary factor causing sage-grouse population declines [5] so research has focused on reproduction to clarify how habitat influences reproductive success.

Nesting success is one of the primary factors influencing reproductive success and sage-grouse population dynamics $[8,9]$. Nest success varies greatly across the geographic range with estimates between $15-86 \%$ of nests hatching $\geq 1$ chick [1]. This variability may be due to differences in vegetation structure among areas. Females select nest sites with greater shrub cover than the surrounding habitat [10-13] and nest success appears to be associated with adequate shrub and grass cover which provide concealment from predators but also allows the hens to escape predators $[9,13,14]$.

We investigated factors hypothesized to influence sagegrouse nest success in the Montana Mountains. Potential relationships between habitat characteristics and nest outcome were examined at two spatial scales: the nest shrub and the area surrounding the nest site. Our aims were to improve our understanding of factors likely influencing sage-grouse population dynamics and to provide managers with information to maintain suitable habitat for nesting that can lead to restoration of sage-grouse populations across their geographic range. 


\section{STUDY SITE}

The Montana Mountains are located $18 \mathrm{~km}$ northwest of

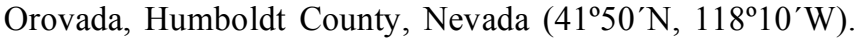
As part of the Lone Willow Population Management Unit managed by the U.S. Bureau of Land Management, the area has been on a rest-rotational system since the 1960s. The core study area encompassed approximately 100,792 hectares ranging from $1200 \mathrm{~m}$ to $2300 \mathrm{~m}$ in elevation. Annual precipitation was circa $22 \mathrm{~cm}$ and average temperatures ranged from $-8^{\circ} \mathrm{C}$ in January to $33^{\circ} \mathrm{C}$ in July.

Vegetation typical of shrub-steppe habitats in southeast Oregon and northern Nevada included low sagebrush (Artemisia arbuscula), mountain big sagebrush (A. tridentata vaseyana), and Wyoming big sagebrush (A. t. wyomingensis). Other shrub species, including antelope bitterbrush (Purshia tridentata), western snowberry (Symphoricarpos occidentalis) and rabbitbrush (Chrysothamnus spp.), were dispersed throughout the site. Common forbs included Agoseris spp., Crepis spp., Phlox spp., Lupinus spp., and Astragulus spp. Grasses included bluegrass (Poa spp.), fescue (Festuca spp.), bluebunch wheatgrass (Pseudoroegneria spicata), needlegrass (Stipa spp.), giant wildrye (Leymus cinereus), and bottlebrush squirreltail (Elymus elymoides).

\section{MATERIALS AND METHODOLOGY}

\section{Data Collection}

Female sage-grouse were trapped and radio-marked in March and April, 2004-5, prior to nest initiation. Trapping efforts targeted known leks and birds were captured opportunistically. Females were captured using a spotlighting technique modified from [15]. We assumed our sample of birds was a representative sample of reproductive females in the Montana Mountains because hens were captured throughout the study site. We fitted birds with 21-g necklace-style radio transmitters (Advanced Telemetry Systems, Inc., Isanti, MN) and a numbered aluminum Nevada Department of Wildlife band. Radio-marked hens were monitored throughout the reproductive period (March - July) for nest initiation and outcome. Every 3-7 days, we located radio-marked females using a portable receiver and 3-element Yagi antenna. Once a hen was found nesting, we monitored the nest from $>20 \mathrm{~m}$ for indications of nest depredation or hatching. Clutch size was determined opportunistically when a hen was found away from her nest, when a female was inadvertently flushed from her nest, or after hatching. We sampled all nests found for radio-marked hens. Our sample of nests was distributed throughout the study site and nesting period (April - June). Unsuccessful hens were monitored for renesting attempts through mid-July. All nests were categorized as successful ( $\geq 1$ egg hatched) or unsuccessful, and after each nest hatched or failed, vegetation characteristics were measured within a circular, $78.5-\mathrm{m}^{2}$ plot surrounding the nest. We estimated the percent cover of sagebrush and grass within this area using line-intercept and Daubenmire frame methods $[16,17]$. The intercept distance of all shrubs along 2 perpendicular, $10-\mathrm{m}$ transects centered at the nest was used to calculate sagebrush cover, and $1020 \times 50-\mathrm{cm}$ frames equidistantly spaced along the transects were used to determine the percent grass cover. We categorized sagebrush cover as short $(<40 \mathrm{~cm})$ or tall $(\geq 40 \mathrm{~cm})$. To investigate the influence of vegetation characteristics at the nest and the vegetation surrounding the nest site, we divided the $78.5-\mathrm{m}^{2}$ circular plot into 2 areas [18]. The circular plot immediately surrounding the nest with $1-\mathrm{m}$ radius $\left(\sim 3 \mathrm{~m}^{2}\right)$ was classified as $1-\mathrm{M}$, and the remaining area delineated by the $5-\mathrm{m}$ radius sample transect, excluding the nest plot $\left(\sim 75.5 \mathrm{~m}^{2}\right)$, was classified as 5-M.

Nest initiation rates were calculated from the total number of radio-marked hens available for nesting and the number of females that initiated nests. Apparent nest success was calculated from the number of successful nests $(\geq 1$ chick hatched) and the total number of nests laid, including renests. Renesting initiation rates were calculated from the birds that remained in the sample and attempted to renest after initial nests failed. Additionally, we calculated a Mayfield estimate for nest survival for sampled nests [19] by counting known exposure days for monitored nests and used an incubation period of 27 days (median incubation period, [1]). Mean clutch size was calculated only from successful nests because of the uncertainty of original clutch size after predation events.

We pooled data from the two study years because our primary interest was in variation in vegetation characteristics and annual differences accounted for part of this variation. We calculated mean values and standard errors for habitat characteristics including grass, sagebrush and total shrub cover, and the proportion of tall sagebrush to total sagebrush.

\section{Data Analyses}

We used logistic regression to calculate the change in odds of nest success due to the influence of vegetation characteristics at 1-M and 5-M plots. Akaike's Information Criterion, adjusted for small sample size $\left(\mathrm{AIC}_{c}\right)$, was used to infer the relative importance of vegetation characteristics based on variables present in top competitive models [20]. Models were derived from explanatory variables including total sagebrush canopy cover at 1-M and 5-M plots, proportion of tall sagebrush to total sagebrush cover at 1-M and 5-M plots, total grass cover at 1-M and 5-M plots, and interaction variables for total cover of tall sagebrush at 1-M and 5-M plots (Table 1).

We screened variables for multicollinearity prior to developing the candidate model set and examined a matrix of scatter plots for all explanatory variables to look for possible relationships. If 2 or more variables were correlated (Pearson correlation coefficient: $r>0.60$ ), they were not used together in any model. However, we included correlated variables in the model set among different models when one variable was better at describing a hypothesis than its related variable.

Based on review of previous studies and observations in the field, we developed 16 a priori candidate models to represent potential relationships between vegetation and nest outcome. The models were described by the format:

$$
\operatorname{Logit}(\pi)=\beta+\beta_{1} x_{1}+\beta_{2} x_{2}+\beta_{3} x_{3} \ldots+\beta_{k} x_{k}
$$

where $\beta_{1}$ is the estimate of the effect of explanatory variable $x_{1}$ after accounting for variables $x_{2}$ through $x_{k}$. The response variable, nest outcome, has a Bernoulli distribution, $\mathrm{Y} \sim$ Bernoulli $(\pi)$, and the mean response is $\mu\left\{y \mid x_{1}, \ldots, x_{k}\right\}=\pi$. The variance structure is described by $\operatorname{Var}\left\{y \mid x_{1}, \ldots, x_{k}\right\}=\pi$ 
Table 1. Description of Explanatory Variables Used in the Candidate Model Set to Associate Vegetation Characteristics with Greater Sage-Grouse Nest Outcome, Montana Mountains, NV, 2004-5

\begin{tabular}{|c|c|c|c|}
\hline Plot & Variable Type & Code & Description \\
\hline \hline $1-\mathrm{M}$ & Horizontal cover & SGRASS & Total grass cover \\
\hline $1-\mathrm{M}$ & Horizontal cover & SSAGE & Total sagebrush cover \\
\hline $1-\mathrm{M}$ & Vertical structure & STALLSAGE & Total grass cover \\
\hline $5-\mathrm{M}$ & Horizontal cover & LGRASS & Total sagebrush cover \\
\hline $5-\mathrm{M}$ & Horizontal cover & LSAGE & Proportion of tall sagebrush $(\geq 40 \mathrm{~cm})$ \\
\hline $5-\mathrm{M}$ & Vertical structure & LTALLSAGE & Proportion of tall sagebrush $\times$ Total sagebrush \\
\hline $1-\mathrm{M}$ & Interaction & STALLSAGE $\times$ SSAGE & Proportion of tall sagebrush $\times$ Total sagebrush \\
\hline $5-\mathrm{M}$ & Interaction & LTALLSAGE $\times$ LSAGE & $\%$ \\
\hline
\end{tabular}

$(1-\pi)$. We calculated $\triangle \mathrm{AIC}_{\mathrm{c}}$ values between the best fitting model and remaining models in the candidate set and Akaike's weights $\left(w_{i}\right)$ to determine the relative likelihood of each model.

\section{RESULTS}

Seventy-six of $84(90 \%)$ radio-marked hens initiated at least one nest. Fifty-two unsuccessful nests and 35 successful nests were sampled. Eight nests were abandoned, likely due to our monitoring activities, and were not included in the analysis. Successful nests hatched between 28 April and 21 June with most failed nests due to predation or abandonment. Apparent nesting success was $40 \%$ (35/87), and of the 76 hens that initiated a nest, $46 \%$ were successful (35/76). We estimated the probability of nest success at $36 \%$ [19]. Of the 43 birds that lost their first nest, $37 \%$ attempted a second nest. In 2004, $25 \%$ of the hens attempted to renest and $48 \%$ attempted renests in 2005. No females attempted a third nest in 2004, but in 2005, 3 of 7 birds still alive attempted a third nest. The clutch size for successful nests ranged from $4-10$ eggs $($ mean $=7.3, n=35)$.

We sampled 22 nests that were repeat efforts (e.g. hens that attempted renest(s) during the same season or nested in both study years). These 22 nests were treated as independent due to the complexity of modeling potential dependence between nests from the same hen. To test this assumption, we repeated our analysis using only one nest from each hen, and model selection results and parameter estimates for vegetation characteristics were similar to those presented.

Nests were located in areas with $15.6 \%$ (SE $\pm 1.0, n=$ 87) mean grass cover, $30.2 \%(\mathrm{SE} \pm 1.3, n=87)$ sagebrush cover, and $37.2 \%(\mathrm{SE} \pm 1.5, n=87)$ total shrub cover and were typically placed under shrubs (1-M plot) with greater sagebrush canopy and grass cover than the surrounding area (5-M) (Table 2). Sixty percent $(\mathrm{SE} \pm 4.0, n=87$ ) of sagebrush cover at $1-\mathrm{M}$ plots was $\geq 40 \mathrm{~cm}$. Successful nest sites (1-M plot) had more grass cover $($ mean $=24.2, \mathrm{SE} \pm 4.1, n=$ 35 ) than unsuccessful sites (mean $=14.8, \mathrm{SE} \pm 1.7, n=52$ ). Only 2 variables were highly correlated, proportion of tall sagebrush at 1-M and 5-M plots (Pearson correlation coefficient: $r=0.76, P<0.0001)$.
We calculated the relative likelihood for each model in our candidate set and ranked models accordingly (Table $\mathbf{3}$ ). The best fitting model contained only grass cover at the nest site (1-M plot). The relative likelihood for this model was approximately $0.3\left(w_{i}=0.295\right)$. However, the model that included grass and sagebrush cover at the nest site was very competitive with a similar likelihood $\left(w_{i}=0.266\right)$. This model was approximately twice as likely as the third competing model which contained grass cover at 1-M and 5-M plots $\left(w_{i}=0.125\right)$. The null model, with no explanatory variables, ranked fourth in our model set and had a likelihood of $0.05\left(w_{i}=0.051\right)$. Grass cover at the nest site $(1-\mathrm{M}$ plot $)$ was present in the 3 top models. The estimate for the effect of nest site grass cover on the odds of nest success changed slightly between the top 3 models (Table 4). Using the estimate from the GRASS COVER (1-M) model, grass cover at the nest site increased the odds of nest success 1.03 times for each percentage increase in the amount of grass cover $(95 \%$ CI: 1.005 - 1.059). Sagebrush cover at the nest site (1-M) and grass cover surrounding the nest (5-M plot) were also present in the top models. Grass cover surrounding the nest and sagebrush cover at the nest site both had a slight positive effect on nest success (odds ratio: 1.016, 95\% CI: 0.968 1.068 and $1.017,95 \%$ CI: $0.993-1.043$ respectively).

\section{DISCUSSION}

Grass cover at the nesting shrub likely influences risk of predation by providing scent and visual barriers [9]. In the Montana Mountains, greater sage-grouse nest areas had the minimum amount of grass cover recommended for breeding habitats [21]. We found nests with higher percent grass cover had an increased likelihood of hatching successfully. Our data show an increase of 10 to $20 \%$ grass cover at the nest site (1-M plot) increased the odds of success by $34.3 \%$. This is similar to results found by Gregg [18] in Oregon, where grass cover at nests was greater for successful than unsuccessful nests. The height of the grass cover at nest sites has also been shown to influence nest success $[9,12,14]$ but we did not include grass height because of the potential for temporal variation in height from nest initiation and incubation to vegetation sampling. Hausleitner et al. [22] found a significant change in both grass height and cover from nest 
Table 2. Vegetation Characteristics of Greater Sage-Grouse Nests in the Montana Mountains, NV, 2004-5 at 1-M and 5-M Plots

\begin{tabular}{|c|c|c|c|c|c|}
\hline & Plot & $\begin{array}{c}\text { Grass Cover }(\%) \\
\text { Mean }( \pm \mathrm{SE})\end{array}$ & $\begin{array}{c}\text { Sagebrush Cover }(\%)^{\mathrm{a}} \\
\text { Mean }( \pm \mathrm{SE})\end{array}$ & $\begin{array}{c}\text { Prop. Tall Sagebrush } \\
\text { Mean }( \pm \text { SE })\end{array}$ & $\begin{array}{c}\text { Shrub Cover }(\%)^{c} \\
\text { Mean }( \pm \mathrm{SE})\end{array}$ \\
\hline \multirow[t]{3}{*}{ All Nests } & $(n=87)$ & & & & \\
\hline & $1-\mathrm{M}$ & $18.6(2.0)$ & $52.9(2.2)$ & $0.60(0.04)$ & $61.8(2.1)$ \\
\hline & $5-\mathrm{M}$ & $14.9(1.0)$ & $24.5(1.4)$ & $0.43(0.04)$ & $31.1(1.6)$ \\
\hline \multirow[t]{4}{*}{ Successful Nests } & $(n=35)$ & & & & \\
\hline & $1-\mathrm{M}$ & $24.2(4.1)$ & $54.0(3.9)$ & $0.61(0.07)$ & $62.1(3.5)$ \\
\hline & $5-M$ & $16.6(2.0)$ & $23.8(2.1)$ & $0.48(0.06)$ & $30.5(2.5)$ \\
\hline & Total & $18.1(1.8)$ & $29.8(2.0)$ & $0.54(0.06)$ & $36.8(2.4)$ \\
\hline Unsuccessful Nests & Total & $14.0(1.1)$ & $30.4(1.8)$ & $0.48(0.05)$ & $37.4(1.9)$ \\
\hline
\end{tabular}

${ }^{\text {a }}$ Sagebrush cover included all Artemisia spp.

${ }^{\mathrm{b}}$ Proportion of sagebrush $\geq 40 \mathrm{~cm}$ tall to total sagebrush cover.

${ }^{\mathrm{c}}$ Total shrub cover included Artemisia spp. and other woody shrubs including Purshia spp., Symphoricarpos spp. and Chrysothamnus spp.

${ }^{\mathrm{d}}$ Total included 1-M and 5-M plots.

Table 3. Candidate Models Describing Potential Relationships between Vegetation Characteristics and Greater Sage-Grouse Nest Outcomes in the Montana Mountains, NV, 2004-5. Lower $\Delta \mathrm{AIC}_{c}$ Values Indicate Better Model Fit and $w_{i}$ is Akaike's Weight Describing the Relative Likelihood of a Model

\begin{tabular}{|c|c|c|c|c|}
\hline Model Description & Model Variables & $\mathbf{A I C}_{c}{ }^{\mathrm{a}}$ & $\Delta \mathrm{AIC}_{c}{ }^{\mathrm{b}}$ & $\mathbf{w}_{\mathbf{i}}$ \\
\hline Grass cover (1-M) & SGRASS & 115.795 & 0.000 & 0.295 \\
\hline Grass cover (1-M and 5-M) & SGRASS + LGRASS & 117.522 & 1.727 & 0.125 \\
\hline Null model & No Explanatory Variables & 119.311 & 3.516 & 0.051 \\
\hline Grass cover $(5-\mathrm{M})$ & LGRASS & 119.715 & 3.919 & 0.042 \\
\hline Horizontal cover (1-M and 5-M) & SGRASS + LGRASS + SSAGE + LSAGE & 119.955 & 4.159 & 0.037 \\
\hline Vertical structure (5-M) & LTALLSAGE & 120.246 & 4.451 & 0.032 \\
\hline Sagebrush cover (5-M) & LSAGE & 121.234 & 5.439 & 0.019 \\
\hline Horizontal cover $(5-\mathrm{M})$ & LGRASS + LSAGE & 121.861 & 6.065 & 0.014 \\
\hline Sagebrush cover (1-M and 5-M) & SSAGE + LSAGE & 123.050 & 7.255 & 0.008 \\
\hline $\begin{array}{l}\text { Vertical and horizontal structure }(1-\mathrm{M}) \\
\text { and horizontal cover }(5-\mathrm{M})\end{array}$ & $\begin{array}{c}\text { SGRASS + SSAGE + STALLSAGE + STALLSAGE } \times \\
\text { SSAGE + LGRASS + LSAGE }\end{array}$ & 123.203 & 7.407 & 0.007 \\
\hline Vertical and horizontal structure (5-M) & LGRASS + LSAGE + LTALLSAGE + LTALLSAGE $\times$ LSAGE & 123.344 & 7.549 & 0.007 \\
\hline Total cover of tall sagebrush (1-M) & SSAGE + STALLSAGE + STALLSAGE $\times$ SSAGE & 123.379 & 7.583 & 0.007 \\
\hline Vertical structure (1-M) and sagebrush cover (5-M) & SSAGE + STALLSAGE + STALLSAGE × SSAGE + LSAGE & 125.267 & 9.472 & 0.003 \\
\hline
\end{tabular}

${ }^{a} \mathrm{AIC}_{c}$ is the Akaike's Information Criterion values with small sample bias adjustment (Burnham and Anderson 2002).

${ }^{\mathrm{b}} \Delta \mathrm{AIC}_{c}$ is the difference between a model's $\mathrm{AIC}_{c}$ value and the smallest $\mathrm{AIC}_{c}$ value $\left(\mathrm{AIC}_{c i}-\mathrm{AIC}_{c \text { min }}\right)$. 
Table 4. Relative Likelihoods of the Top 3 Models and Odds Ratios with $95 \%$ Confidence Intervals for the Effect of Total Grass Cover at Greater Sage-Grouse Nests on Nest Outcome, Montana Mountains, NV, 2004-5

\begin{tabular}{|c|c|c|c|c|}
\hline Model & $w_{i}{ }^{\mathrm{a}}$ & $\beta^{\mathrm{b}}$ for Grass Cover at 1-M Plot & Odds Ratio $\left(e^{\beta}\right)^{\mathrm{c}}$ & 95\% CI for Odds Ratio \\
\hline Grass cover (1-M) & 0.295 & 0.0295 & 1.030 & $1.005-1.059$ \\
\hline Grass cover (1-M and 5-M) & 0.125 & 0.0267 & 1.027 & $1.002-1.057$ \\
\hline
\end{tabular}

${ }^{a} w_{i}$ is the Akaike's weight describing the relative likelihood of a model (Burnham and Anderson 2002).

${ }^{\mathrm{b}}$ Parameter estimate.

${ }^{c}$ Odds ratio $=$ the factor by which the odds of a nest hatching successfully changes for every 1-unit increase in grass cover.

initiation to nest cessation but doubted whether these changes were biologically significant.

The amount of sagebrush cover surrounding nests in the Montana Mountains was greater than that reported in most other study areas and exceeded levels recommended for management of breeding habitats $(15-25 \%$, [21]). Sagebrush canopy at the nesting shrub appeared to have a positive effect on nesting success, but the confidence intervals overlapped 1 so the effect of this variable is likely to be small. The importance of sagebrush canopy cover for nest success in other studies has been variable with a positive effect of sagebrush canopy reported from Oregon $[9,14,18]$ but no effect reported in Washington or Canada [12,23]. Even so, most sage-grouse nests are under sagebrush [1,9,10,12,24], so sagebrush is important for nesting sage-grouse, but the degree to which sagebrush cover at nest sites influences nesting success varies. The availability of suitable nest shrubs was not likely a limiting factor for nest success in the Montana Mountains.

There was only weak evidence suggesting grass cover surrounding the nest (5-M plot) had a positive effect on nest success in the Montana Mountains. Our results were similar to those from Oregon, where grass cover surrounding the nest was not different between successful and unsuccessful nests [18]. However, in a Canadian study area less grass cover surrounded the successful nests than the unsuccessful nests [23] but grass cover in the Montana Mountains was less than half that reported in Canada.

The weak relationship between nest success and grass cover surrounding the nest, and the inconsistent results from other areas, indicate that vegetation characteristics surrounding the nest may not be a good predictor of nest outcome across the geographic range of sage-grouse. Females appear to select nest sites based on vegetation characteristics at a fine scale - the nest shrub and associated herbaceous understory [18].

\section{CONCLUSION: MANAGEMENT IMPLICATIONS}

Management strategies aimed at increasing nesting success of greater sage-grouse should focus on increasing grass cover and maintaining shrub communities. Similar to other sage-grouse studies $[9,12,14,18]$, we found nesting success increased as grass cover at the nest increased. Sagebrush cover also had a positive influence on nesting success although the relationship was not conclusive. Proposed management guidelines for proportions of sagebrush cover near nests should be conservative until further studies clarify this relationship. Most nests are placed under sagebrush, so the sagebrush component of nesting habitat is important, but it appears sufficient grass cover is also important for successful nesting, and should be managed accordingly. Management strategies should limit potential disturbances that reduce grass cover or excessively reduce sagebrush cover. Overgrazing, fire, and invasion by exotic grasses that influence the frequency of fire and thereby reduce shrub cover, can all reduce grass and sagebrush cover. With increased grazing intensity, livestock seek out grasses beneath shrubs after foraging on the grasses in the interspaces between shrubs [25]. Excessive livestock grazing could thereby reduce grass cover at nesting shrubs and increase the likelihood of sagegrouse nest predation. Limiting the impacts of livestock grazing by reducing excessive use of reproductive habitat during sage-grouse nesting season and maintaining a diverse mosaic of habitat types across the landscape, could insure sufficient sage-grouse habitat will persist in the event of disturbances.

Our analyses compared vegetation characteristics measured at a fine scale, but successful management of sagegrouse populations must occur at multiple scales and must be able to influence nesting habitat characteristics at a landscape level. Minimally, nesting habitat must have suitable shrubs and sufficient herbaceous understory to provide protection for sage-grouse nests. Further research is needed to relate fine-scale site features to landscape-level characteristics so land managers can apply appropriate management strategies at all spatial scales necessary to conserve populations of this declining species.

\section{ACKNOWLEDGMENTS}

We thank Drs. M. Gregg and S. Petersen for their contributions to this study and manuscript. Three anonymous reviewers provided helpful comments. Funding came from the U.S. Bureau of Land Management and the National Fish and Wildlife Foundation. Nevada Department of Wildlife provided logistical support and assistance. We recognize members of the Nevada Chukar Foundation and Nevada Bighorns Unlimited for their financial contributions and continued interest in sage-grouse research. We are grateful to the Humboldt Hunt Club, particularly D. Ingram, for their support and housing in the field. Finally, we acknowledge the Department of Fisheries and Wildlife at Oregon State University for support of this research. Birds were marked under permits from the U.S. Fish and Wildlife Service and Nevada Department of Wildlife. 


\section{REFERENCES}

[1] Schroeder MA, Young JR, Braun CE. Sage-grouse (Centrocercus urophasianus). In: Poole A, Gill F, Eds. The birds of North America, No. 425. The birds of North America, Inc., Philadelphia, Pennsylvania, USA 1999

[2] Schroeder MA, Aldridge CL, Apa AD, et al. Distribution of sagegrouse in North America. Condor 2004; 106: 363-76.

[3] Dalke PD, Pyrah DB, Stanton DC, Crawford JE, Schlatterer EF. Ecology, productivity, and management of sage grouse in Idaho. $\mathbf{J}$ Wildl Manage 1963; 27: 811-41.

[4] Klebenow DA. Habitat management for sage-grouse in Nevada. World Pheasant Assoc J 1985; 10: 34-46.

[5] Crawford JA, Olson RA, West NE, et al. Ecology and management of sage-grouse and sage-grouse habitat. J Range Manage 2004; 57: $2-19$.

[6] Girard GL. Life history, habitats, and food of the sage-grouse, Centrocercus urophasianus Bonaparte. University of Wyoming Publications No. 3, Laramie, USA 1937.

[7] Rassmussen DI, Griner LA. Life History and management studies of the sage grouse in Utah, with special reference to nesting and feeding habits. Transactions of the Third North American Wildlife Conference 14-17 February 1938. American Wildlife Institute, Washington D.C., USA 1938.

[8] Crawford JA, Lutz RS. Sage grouse population trends in Oregon, 1941-1983. Murrelet 1985; 66: 69-74.

[9] Gregg MA, Crawford JA, Drut MS, DeLong AK. Vegetational cover and predation of sage grouse nests in Oregon. J Wildl Manage 1994; 58: 162-6.

[10] Klebenow DA. Sage grouse nesting and brood habitat in Idaho. J Wildl Manage 1969; 33: 649-62.

[11] Wakkinen WL. Nest site characteristics and spring-summer movements of migratory Sage grouse in Southeastern Idaho. Thesis, University of Idaho, Moscow, USA 1990.

[12] Sveum CM, Edge WD, Crawford JA. Nesting habitat selection by sage grouse in south-central Washington. J Range Manage 1998; 51: 265-9.
[13] Holloran MJ, Heath BJ, Lyon AG, Slater SJ, Kuipers JL, Anderson $\mathrm{SH}$. Greater sage-grouse nesting habitat selection and success in Wyoming. J Wildl Manage 2005; 69: 638-49.

[14] DeLong AK, Crawford JA, DeLong DC. Relationships between vegetational structure and predation rates of artificial sage grouse nests. J Wildl Manage 1995; 59: 88-92.

[15] Giesen KM, Schoenberg TJ, Braun CE. Methods for trapping sagegrouse in Colorado. Wildl Soc Bull 1982; 10: 224-31.

[16] Canfield RH. Application of the line intercept method in sampling range vegetation. J For 1941; 39: 386-94.

[17] Daubenmire RF. A canopy-coverage method of vegetation analysis. Northwest Sci 1959; 33: 224-7.

[18] Gregg MA. Use and selection of nesting habitat by sage-grouse in Oregon. Thesis, Oregon State University, Corvallis, USA 1991.

[19] Mayfield HF. Suggestions for calculating nest success. Wilson Bull 1975; 87: 456-66.

[20] Burnham KP, Anderson DR. Model selection and multimodel inference: a practical information-theoretic approach. $2^{\text {nd }}$ ed. Springer-Verlag, New York, USA 2001.

[21] Connelly JW, Schroeder MA, Sands AR, Braun CE. Guidelines to manage sage-grouse populations and their habitats. Wildl Soc Bull 2000; 28: 967-85.

[22] Hausleitner D, Reese KP, Apa AD. Timing of vegetation sampling at greater sage-grouse nests. Rangeland Ecol Manage 2005; 58: 553-6.

[23] Aldridge CL, Brigham RM. Sage-grouse nesting and brood habitat use in southern Canada. J Wildl Manage 2002; 66: 433-44.

[24] Connelly JW, Wakkinen WL, Apa AD, Reese KP. Sage grouse use of nest sites in southeastern Idaho. J Wildl Manage 1991; 55: 521-

[25] France KA. Interspace/under-canopy foraging patterns of beef cattle in sagebrush communities: Implications to sage-grouse nesting habitat. Thesis, Oregon State University, Corvallis, USA 2005.

(C) Rebholz et al.; Licensee Bentham Open

This is an open access article licensed under the terms of the Creative Commons Attribution Non-Commercial License (http://creativecommons.org/licenses/ by-nc/3.0/) which permits unrestricted, non-commercial use, distribution and reproduction in any medium, provided the work is properly cited. 